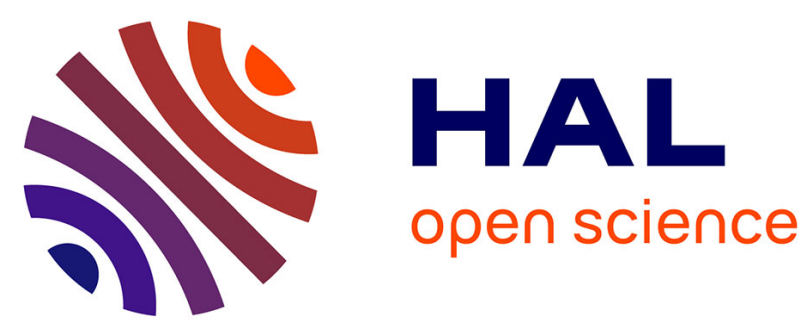

\title{
A Low Power Cryocooled Autonomous Ultra-Stable Oscillator
}

Christophe Fluhr, Benoît Dubois, Serge Grop, Julien Paris, Guillaume Le Tetu, Vincent Giordano

\section{To cite this version:}

Christophe Fluhr, Benoît Dubois, Serge Grop, Julien Paris, Guillaume Le Tetu, et al.. A Low Power Cryocooled Autonomous Ultra-Stable Oscillator. Cryogenics, 2016, 80 (1), pp.164 - 173. hal02182843

\section{HAL Id: hal-02182843 \\ https://hal.science/hal-02182843}

Submitted on 13 Jul 2019

HAL is a multi-disciplinary open access archive for the deposit and dissemination of scientific research documents, whether they are published or not. The documents may come from teaching and research institutions in France or abroad, or from public or private research centers.
L'archive ouverte pluridisciplinaire HAL, est destinée au dépôt et à la diffusion de documents scientifiques de niveau recherche, publiés ou non, émanant des établissements d'enseignement et de recherche français ou étrangers, des laboratoires publics ou privés. 


\title{
A Low Power Cryocooled Autonomous Ultra-Stable Oscillator
}

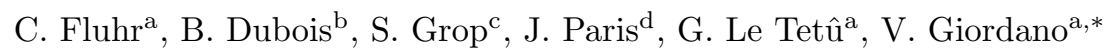 \\ ${ }^{a}$ FEMTO-ST Institute, Time 8 Frequency Dpt., ENSMM 26 Chemin de l'Epitaphe, 25000 \\ Besançon, France \\ ${ }^{b}$ FEMTO Engineering, 32 Avenue de l'Observatoire 25000 Besançon, France \\ ${ }^{c}$ Alemnis GmbH, Feuerwerkerstrasse 39, 3602 Thun, Switzerland \\ ${ }^{d}$ My Cryo Firm SARL, 104 Avenue de la Résistance, 93100 Montreuil, France
}

\begin{abstract}
We present the design and the preliminary evaluation of a cryostat equipped with a low power Pulse-Tube cryocooler intended to maintain near $5 \mathrm{~K}$ a high-Q factor sapphire microwave resonator. This cooled resonator constitutes the frequency reference of an ultra-stable oscillator presenting a short term fractional frequency stability of better than $1 \times 10^{-15}$. The proposed design enables to reach a state-of-the-art frequency stability with a cryogenic oscillator consuming only $3 \mathrm{~kW}$ of electrical power.
\end{abstract}

Keywords: Ultra-stable oscillator, Pulse-Tube cryocooler, frequency stability.

\section{Introduction}

The advent of reliable two-stage cryocoolers makes it possible to replace the out-dated liquid helium facilities in number of very demanding scientific applications [1, 2]. In the field of Time and Frequency metrology, the most stable frequency source is based on a microwave whispering gallery mode sapphire resonator cooled near $6 \mathrm{~K}[3]$. Provided the resonator environment is sufficiently

\footnotetext{
* Corresponding author

Email address: giordano@femto-st.fr (V. Giordano)

${ }^{1}$ This work has been realized in the frame of the ANR projects: Equipex Oscillator-Imp and Emergence ULISS-2G. The authors would like to thank the Council of the Région de Franche-Comté for its support to the Projets d'Investissements d'Avenir and the FEDER (Fonds Européen de Développement Economique et Régional) for funding one CSO.
} 
free of vibration and temperature fluctuation, the Cryogenic Sapphire Oscillator $(\mathrm{CSO})$ presents a short term fractional frequency stabilitiy of better than $1 \times 10^{-15}$. The recent demonstration of a low maintenance CSO based on a pulse-tube cryocooler paves the way for its deployment in real field applications [4, 5, 6. Nevertheless, the current CSO technology needs to be improved to enable the largest range of potential users. The large electrical consumption (three-phase $8 \mathrm{~kW}$ peak / $6 \mathrm{~kW}$ stable operation) of the current system is the main obstacle to the deployment of the CSO technology.

In this paper, we describe an optimized cryostat designed to operate with a low consumption cryocooler requiring only $3 \mathrm{~kW}$ single phase of input power to cool down to $4 \mathrm{~K}$ a sapphire resonator. We demonstrate that the proposed design is compatible with reaching a state-of-the-art frequency stability.

\section{CSO design and cryostat specifications}

The CSO is based on a dielectric resonator made in pure sapphire $\left(\mathrm{Al}_{2} \mathrm{O}_{3}\right)$ monocrystal. Sapphire presents the lowest dielectric losses in X-band, and thus, permits building high Q-factor microwave resonators. A typical $10 \mathrm{GHz}$ cylindrical resonator is shown in Fig. 1. It is $54 \mathrm{~mm}$ diameter and $30 \mathrm{~mm}$ thick

25 [7. The resonator is placed in the center of a copper cavity whose external dimensions are $120 \mathrm{~mm} \times 70 \mathrm{~mm}$.

The confinement of the electromagnetic field inside the sapphire is ensured by the use of a high-order resonance mode called whispering gallery mode. Near $4 \mathrm{~K}$, the Q- factor reaches $10^{9}$, and leads to exceptional short-term stability. For 30 longer integration times, the resonator frequency is affected by environmental perturbations and especially by the temperature fluctuations. The sapphire resonator frequency shows near $6 \mathrm{~K}$ a turnover temperature for which the resonator sensitivity to temperature variations nulls at first order. The appearance of this turning point results from the presence in $\mathrm{Al}_{2} \mathrm{O}_{3}$ of paramagnetic impurities as ${ }_{35} \mathrm{Cr}^{3+}$ or $\mathrm{Mo}^{3+}$. These ions introduce a magnetic susceptibility whose thermal 

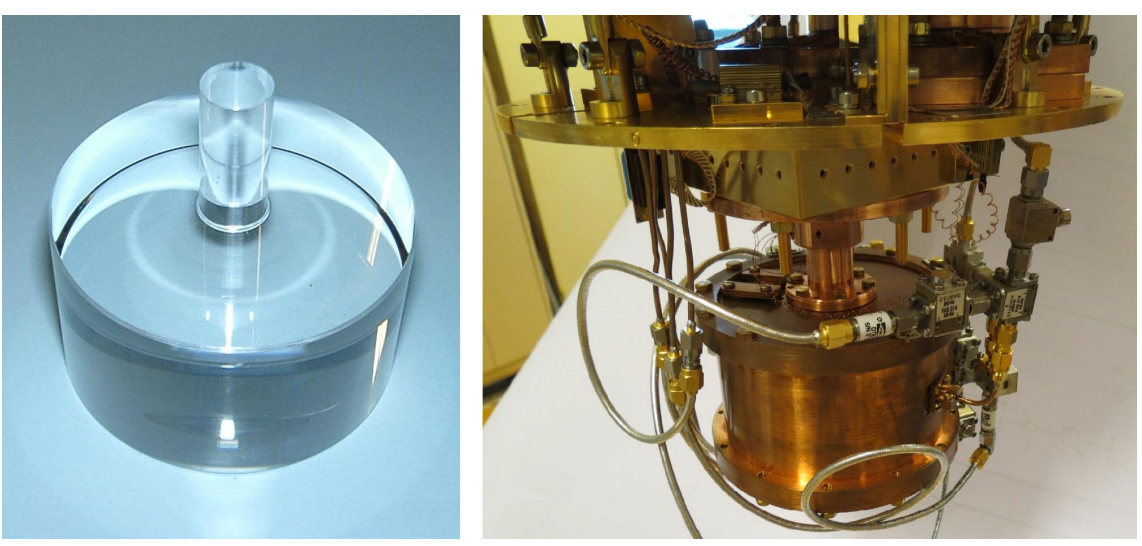

Figure 1: Left: $10 \mathrm{GHz}$ Sapphire resonator. The $10 \mathrm{~mm}$ spindle is used to maintain the resonator in its cavity. Right: Inside the $6 \mathrm{~kW}$ cryostat: the cavity attached to the cryocooler $2^{\text {nd }}$ stage.

sensitivity is opposite to the natural sapphire sensitivity [8, 9]. The resonator is used in transmission mode in a regular oscillator loop. The amplifier stage is placed outside the cryostat at room temperature. The system is completed by two active control loops that stabilize the phase (Pound servo) and the power of 40 the signal injected in the resonator. Details on the design and on the techniques that have to be applied to get an ultimate frequency stability can be found in [7, 10, 11, 12. The main requirements for the cryostat are:

- Autonomy: some applications as Very Long Baseline Interferometry (VLBI), are operating in remote sites with no liquid Helium facilities. The use of a cryocooler is mandatory.

- Experimental Volume and Mass to be cooled: The volume necessary for the implementation of the microwave cavity is a cylinder of diameter $180 \mathrm{~mm}$ and $150 \mathrm{~mm}$ in height. The mass of the cavity is approximately $6 \mathrm{~kg}$.

- Minimum achievable temperature: The exact operating temperature depends on the type and density of the paramagnetic impurities contained in the resonator. For the best resonator material, it is typically found between $5 \mathrm{~K}$ and $8 \mathrm{~K}$. To be able to efficiently stabilize the resonator at $5 \mathrm{~K}$, the 
minimum achievable temperature has been set to $4.5 \mathrm{~K}$.

- Temperature stability: The residual resonator temperature sensitivity imposes

a temperature stability of $1 \mathrm{mK}$ rms, for integration times between $1 \mathrm{~s}$ and $1000 \mathrm{~s}$.

- Displacement or Acceleration: Assuming a stimulus well below the mechanical resonances of the sapphire piece, the sensitivity of the resonator frequency to acceleration is $3.2 \times 10^{-10} / \mathrm{g}$ [13. For a mechanical vibration at 1 $\mathrm{Hz}$, which is almost the typical cryocooler cycle frequency, the acceptable maximum displacement is $1 \mu \mathrm{m}$.

- Electrical consumption : Less than $3.6 \mathrm{~kW}$, which is in most of the places the maximal power for a common single phase power outlet.

\section{Cryostat Design Overview}

The main drawbacks in the use of a cryocooler are the mechanical and thermal disturbances induced during the thermodynamical cycle. A Pulse-Tube cryocooler with a remote rotay valve is preferred as it has no moving part, and thus induces less vibrations that a Gifford-McMahon cryocooler. Our design is based on a $3 \mathrm{~kW}$ PT-403 cryocooler from Cryomech delivering typically $0.25 \mathrm{~W}$ at $4 \mathrm{~K}$. For this cryocooler the frequency of the thermodynamical cycle is about $1.4 \mathrm{~Hz}$. The levels of mechanical displacement and temperature fluctuations induced by the gas flow inside the Pulse-Tube are still too large. Typical displacements of the $2^{\text {nd }}$ stage cold plate are $25 \mu \mathrm{m}$ peak-to-peak in the vertical direction and $12 \mu \mathrm{m}$ peak-to-peak in the horizontal one [14. To maintain the resonator displacement well below $1 \mu \mathrm{m}$ a mechanical damping of at least $40 \mathrm{~dB}$ is mandatory. The temperature variation on the PT $2^{\text {nd }}$ stage is typically $100 \mathrm{mK} \mathrm{rms}$.

Several solutions have been proposed to mitigate these problems. Caparelli in [15] has designed an active system which provides more than $40 \mathrm{~dB}$ attenuation of the PT vibrations. Wang and Hartnett designed a new cryostat where the 
heat link between the PT $2^{\text {nd }}$ stage and the cryogenic device is achieved with a liquid-gas phase change of Helium [16]. These sophisticated solutions provide a high degree of vibration attenuation, but are complex and not easy to implement. Our main objective is to develop a cryostat as simple as possible avoiding 85 a high cost and a complex optimisation. Thus we choose a simple passive filtering inspired from Tomaru et al. [17. Fig. 2 shows an overview of the CSO cryostat.

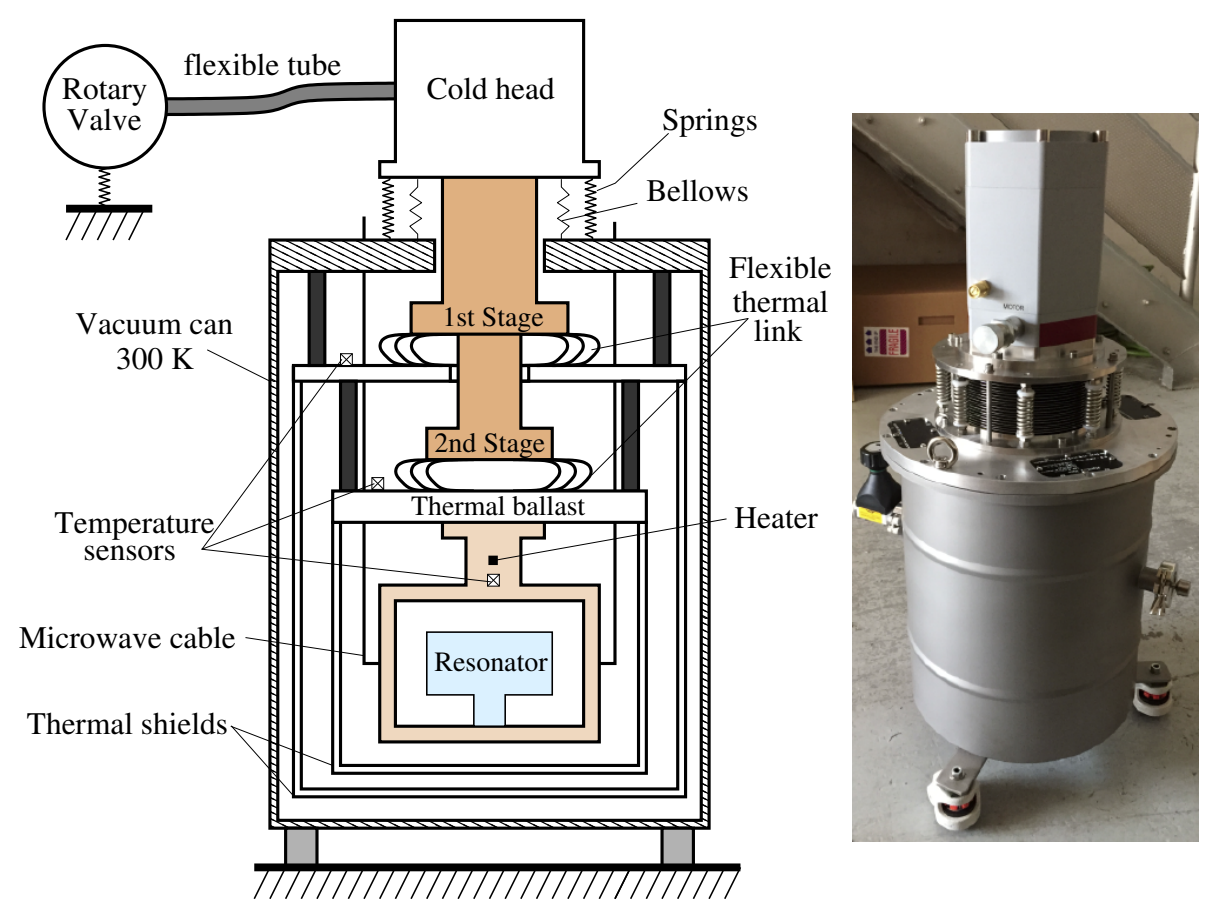

Figure 2: CSO cryostat: design overview (left), picture of the prototype (right). The rotary valve is located remotely from the cryostat. The resonator is linked to the external circuits by 4 microwave cables: two are needed for the oscillating loop. The others are needed for the control of the power and the phase of the injected signal (only two cables are represented).

The microwave resonator is rigidly attached to the top flange of the cryostat whose external surrounding walls are made as rigid as possible keeping 90 reasonable mass and space. The rotary valve unit, which could generate large vibrations, is separated from the cold-head. The cold-head itself still remains 
an important source of vibrations. Thus it is supported by a set of 8 springs providing the vibration insulation. A bellows makes the connection with the vacuum can. The remaining vibrations come from the pressure oscillation in the pulse tube and regenerator transmitted to the cold-stage through thermal links. The vibration reduction is obtained by using flexible metal heat links (copper braids). The temperature variations are passively filtered by the thermal ballast constituted by the stainless steel top flange of the $2^{\text {nd }}$ stage thermal shield. Associated with the thermal resistance of the flexible thermal link it is equivalent to a first order filter. The cavity is attached to the thermal ballast. A thermal sensor and a $25 \Omega$ resistive heater are anchored in the cavity foot. They allow the control of the resonator temperature. Four microwave UT-085 semirigid $\mathrm{Be} / \mathrm{Cu}$ cables link the resonator assembly to the external circuits. These cables are thermalized on each stage. To optimize this design with regard to the CSO performance, trade-offs have to be made between the vibration attenuation, the thermal conductance of the links and the ballast thermal mass.

\subsection{Mechanical decoupling}

As a first approach, we neglect the displacement of the PT $1^{\text {st }}$ stage and thus consider only the $2^{\text {nd }}$ stage suspension. Fig. 3 a shows how the experiment of mass $M$ can be suspended from the frame by a set of three vertical rigid rods of length $L$.

a)

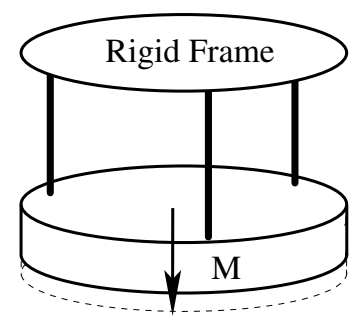

b)

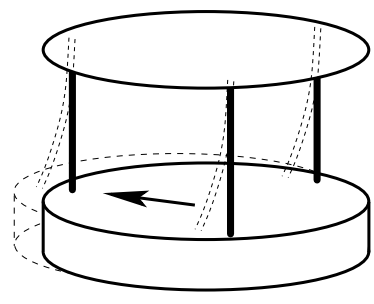

c)

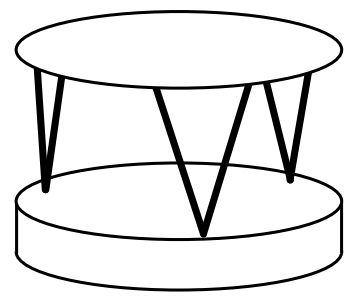

Figure 3: a) Simplified model of $2^{\text {nd }}$-stage suspension. The experiment to be cooled has a mass M. a) Displacement induced in the axial direction. b) Displacement induced in a transverse direction. c) 6 tilted rods suspension to stiffen the suspension in the transverse direction. 
The mass $M \sim 10 \mathrm{~kg}$ includes the microwave resonator, the thermal ballast and the $2^{\text {nd }}$ stage thermal shield. The rods counteract any axial displacement with a stiffness $k_{0}$. The mass $M$ is also linked to the PT $2^{\text {nd }}$ stage by the flexible thermal link presenting a stiffness $k_{1}$. An over-simplified mechanical model for the $2^{\text {nd }}$ stage is represented in Fig. 4
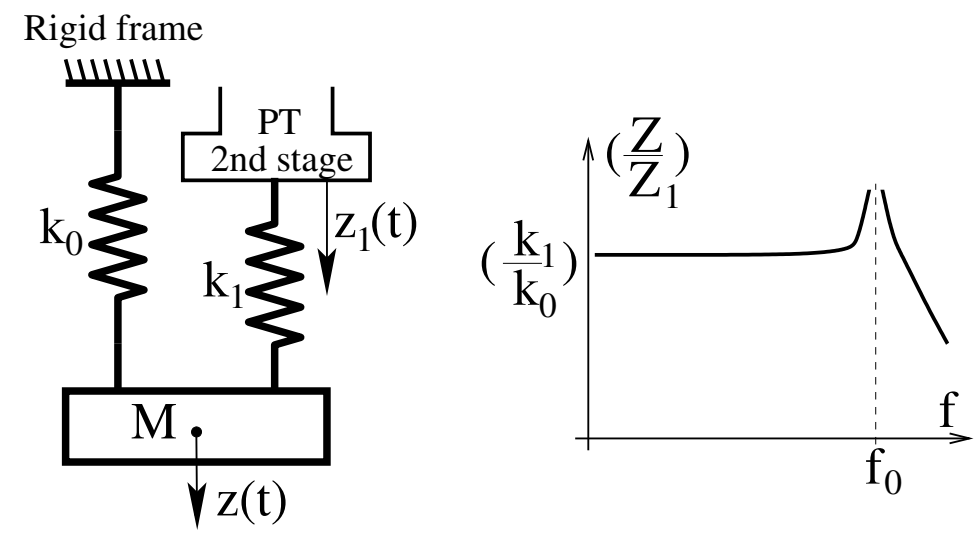

Figure 4: a) Simplified mechanical model. Assuming a displacement $z_{1}(t)=Z_{1} \cos 2 \pi f t$ of the PT $2^{\text {nd }}$ stage, the displacement of the device will be $z(t)=Z \cos 2 \pi f t$. For $k_{1} \ll k_{0}$, a simple calculation gives the ratio $Z / Z_{1}=k_{1} / k_{0}$ for $f \ll f_{0}=1 / 2 \pi \sqrt{k_{0} / M}$.

At a frequency below the mechanical resonance frequency $f_{0} \sim 1 / 2 \pi \sqrt{k_{0} / M}$, the attenuation of the vertical displacement is given by the stiffness ratio: $k_{1} / k_{0}$. In the following, these stiffness are evaluated by considering beams subjected to traction or flexion. The useful equations are [18]:

$$
\text { Traction : } k=\frac{E S}{L} ; \text { Flexion : } k=\frac{3 E I}{L^{3}}
$$

where $E$ is the Young's Modulus, $L$ is the beam length, $S$ its cross-section and $I$ the second moment of area of the beam's cross-section. The distance separating the two stages in a typical commercial PT set the rod length to $L \approx 10 \mathrm{~cm}$. Different materials have been considered (see Tab. 1): 304L stainless steel (SS) $8.5 \times 7.8 \mathrm{~mm}$ tubes, G10 fiber or Mylar $8.5 \mathrm{~mm}$ diameter rods.

We designed OHFC copper braids to realize the thermal link to the PT $2^{\text {nd }}$ stage. The braid is made of $\Phi=0.05 \mathrm{~mm}$ diameter OFHC wires. Its length 
Table 1: Mechanical parameters of the suspension rods and wires.

\begin{tabular}{lrrr} 
& $\begin{array}{r}E \\
(\mathrm{GPa})\end{array}$ & $\begin{array}{r}S \\
\left(\mathrm{~mm}^{2}\right)\end{array}$ & $\begin{array}{r}I \\
\left(\mathrm{~mm}^{4}\right)\end{array}$ \\
\hline Mechanical Suspensions: & & & \\
304 L SS tubes & 210.0 & 9.0 & 74.5 \\
G-10 rods & 36.0 & 56.7 & 256.2 \\
Mylar rods & 8.8 & 56.7 & 256.2 \\
\hline Thermal link: & & & \\
OFHC wires & 140.0 & $2 \times 10^{-3}$ & $3 \times 10^{-7}$ \\
\hline
\end{tabular}

is $5 \mathrm{~cm}$, its cross-section is $5.25 \mathrm{~mm}^{2}$ for about 2700 wires. The ends of the braid are crimped in OHFC copper heads that can be firmly screwed on the pieces to be thermally linked. Depending on the available space, between 10 and 20 braids can be implemented between the PT $2^{\text {nd }}$ stage and the device to be cooled. Neglecting the curvature of the wires and the friction between them, each elementary wire can be treated like an independent beam submitted to a flexion force. Considering 16 braids, i.e. 43, 200 wires, the stiffness of the thermal link is $k_{1} \approx 50 \mathrm{~N} / \mathrm{m}$. The thermal resistance of the braids is $1 \mathrm{~K} / \mathrm{W}$. Conversely the suspension rods are submitted to traction. As demonstrated in Tab. 2, it is easy to get a high axial stiffness such as $k_{0} \gg k_{1}$ even with non-metallic materials.

Table 2: Mechanical characteristics for several suspensions using vertical beams. $L=10 \mathrm{~cm}$.

\begin{tabular}{lcccc} 
& \multicolumn{2}{c}{ axial mode } & \multicolumn{2}{c}{ pendulum mode } \\
& $k_{0}$ & $f_{0}$ & $k_{T}$ & $f_{T}$ \\
& $(\mathrm{~N} / \mathrm{m})$ & $(\mathrm{Hz})$ & $(\mathrm{N} / \mathrm{m})$ & $(\mathrm{Hz})$ \\
\hline 304 L SS tubes & $58 \times 10^{6}$ & 379 & $140 \times 10^{3}$ & 19 \\
G-10 rods & $61 \times 10^{6}$ & 394 & $83 \times 10^{3}$ & 14 \\
Mylar rods & $15 \times 10^{6}$ & 194 & $20 \times 10^{3}$ & 7 \\
\hline
\end{tabular}

In every case the axial displacement is strongly attenuated as $k_{0} \gg k_{1}$. How- 
ever we should also consider the transverse displacement as shown in Fig. 3 b. In this direction the same rods have a much lower stiffness $k_{T}$. The first transverse mode (pendulum mode) has thus a low resonance frequency $f_{T} \sim 1 / 2 \pi \sqrt{k_{T} / M}$ (see Tab. 2). Transverse modes can be excited by the PT $2^{\text {nd }}$-stage displacement and can induce detrimental effects on the CSO frequency stability at short integration time. Fig. 3 c shows the solution we implemented to stiffen the suspension in the transversal direction. Each vertical rod is replaced by two rods forming a $\mathrm{V}$ (V-shaped suspension). Whatever the direction of the mechanical disturbance, the 6 tilted rods are submitted both to traction and flexion notably increasing the stiffness for a transverse displacement.

\subsection{Thermal Analysis}

Fig. 5 shows the thermal model we used to evaluate if a $3 \mathrm{~kW}$ cryocooler is able to maintain the resonator at its turnover temperature.

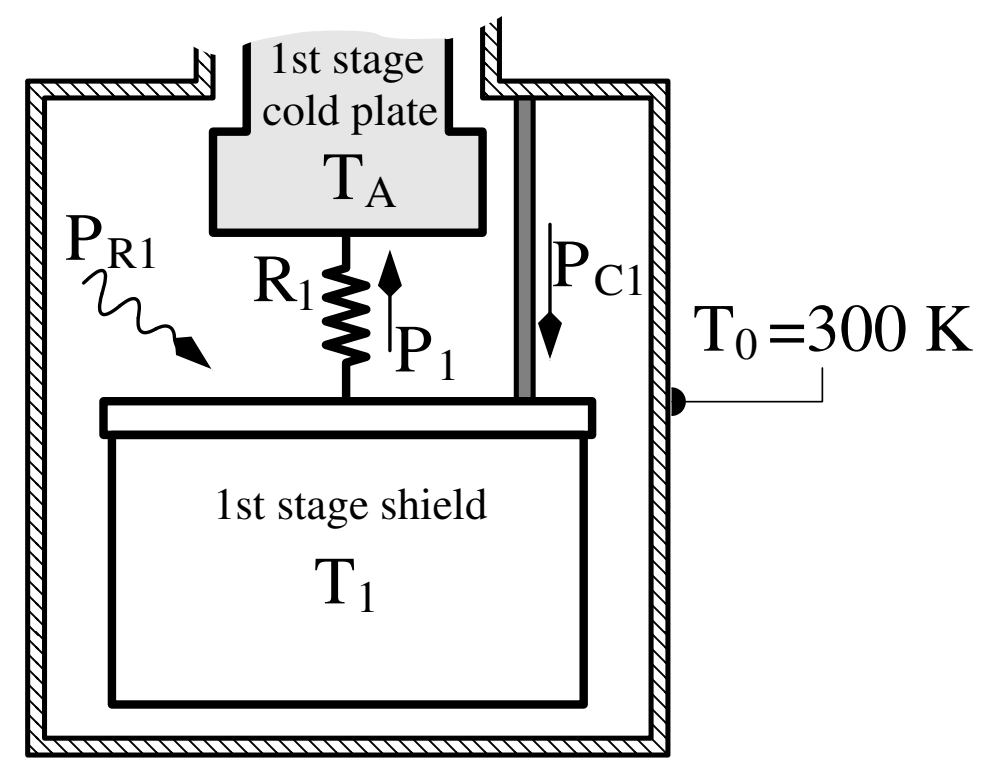

Figure 5: Thermal model for the $1^{\text {st }}$ stage. 


\subsection{1. $1^{\text {st }}$ stage}

shield. The table 3 gives the characteristics: temperature, material, area and emissivity assumed for each surface entering in the thermal model.

\begin{tabular}{ccccc} 
Table 3: Characteristics of the surfaces entering in the thermal model \\
\hline & Temperature & Material & $\begin{array}{c}\text { Area } \\
\left(\mathrm{m}^{2}\right)\end{array}$ & $\epsilon$ \\
\hline Cryostat & $T_{0}=300 \mathrm{~K}$ & $306 \mathrm{SS}$ & 0.52 & 0.20 \\
$1^{\text {st }}$ stage & $T_{1}$ & Aluminium & 0.35 & 0.08 \\
$2^{\text {nd }}$ stage & $T_{2}$ & Aluminium & 0.18 & 0.04 \\
\hline
\end{tabular}

At the thermal equilibrium a power $P_{1}=P_{C 1}+P_{R 1}$ is transferred to the thermal shield. $P_{C 1}$ is the heat flow conducted through the suspension rods and

The power $P_{1}$ is evacuated by the $1^{\text {st }}$ stage through $R_{1} \sim 1 \mathrm{~K} / \mathrm{W}$ the thermal resistance of the braids. We consider the PT-403 cryocooler, which is the least powerful model of the range from CryoMech. $T_{A}$, the temperature of the PT $1^{\text {st }}$ stage, depends on the applied heat flow $P_{1}$. The function $T_{A}\left(P_{1}\right)$ can approximated from the cryocooler capacity curve provided by the manufacturer [19]. On the same figure, we plot the function $T_{1}=g\left(P_{1}\right)=T_{A}\left(P_{1}\right)+R_{1} P_{1}$. For a given thermal configuration the intersection of the two functions $f\left(P_{1}\right)$ and $g\left(P_{1}\right)$ gives the operating point $\left(P_{1}, T_{1}\right)$. With the Mylar suspension, the $1^{\text {st }}$ stage shield will stabilize at $80 \mathrm{~K}$ with a $3 \mathrm{~kW}$ PT cryocooler while it will be $57 \mathrm{~K}$ with a $6 \mathrm{~kW}$ unit. In this configuration, the heat transferred by radiation is the dominant process. Thus the operating point is not greatly affected by the 


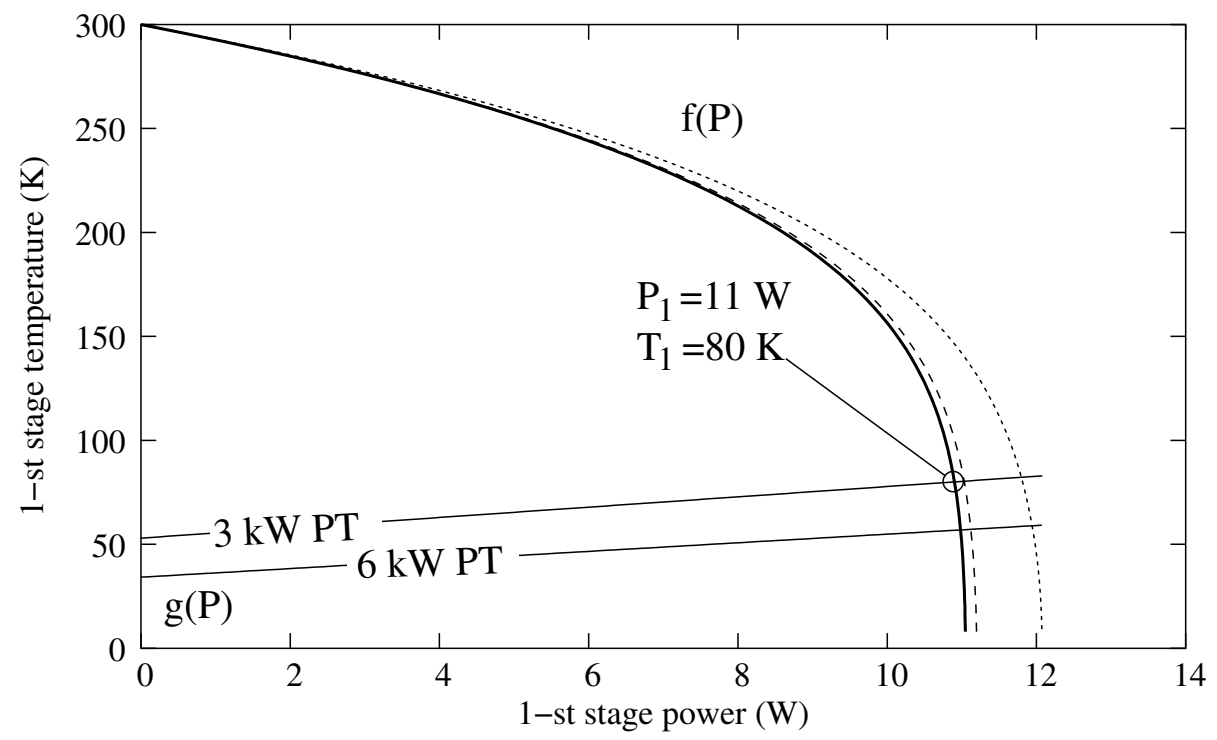

Figure 6: Simulation of the PT $1^{\text {st }}$ stage. $f(P)$ for several suspensions: stainless steel (dotted line), G-10 fiber (dashed line), Mylar (bold line). $g(P)$ for two types of cryocooler consuming 3 and $6 \mathrm{~kW}$ respectively (solid lines).

suspension material.

\subsection{2. $2^{\text {nd }}$ stage}

The $2^{\text {nd }}$ stage is analysed with the same method. It is surrounded by the $1^{\text {st }}$ stage shield assumed at the temperature $T_{1}$ previously determined, i.e. $T_{1}=80 \mathrm{~K}$ (see Fig. 7).

For the $2^{\text {nd }}$ stage, the conduction through the suspension rods is the dominant process. With stainless steel rods the $2^{\text {nd }}$ stage will stabilize at $4.1 \mathrm{~K}$, which is just below the specification, i.e. $T_{2}<4.5 \mathrm{~K}$. A lower temperature $T_{2}=3.5 \mathrm{~K}$ is obtained with G10-fiber or Mylar suspensions.

In our preliminary prototype we choose to use Mylar suspensions for both stages. Following the simple previous analysis, Mylar rods allow of reach the temperature specification with a sufficient margin. Moreover the V-shaped My- 


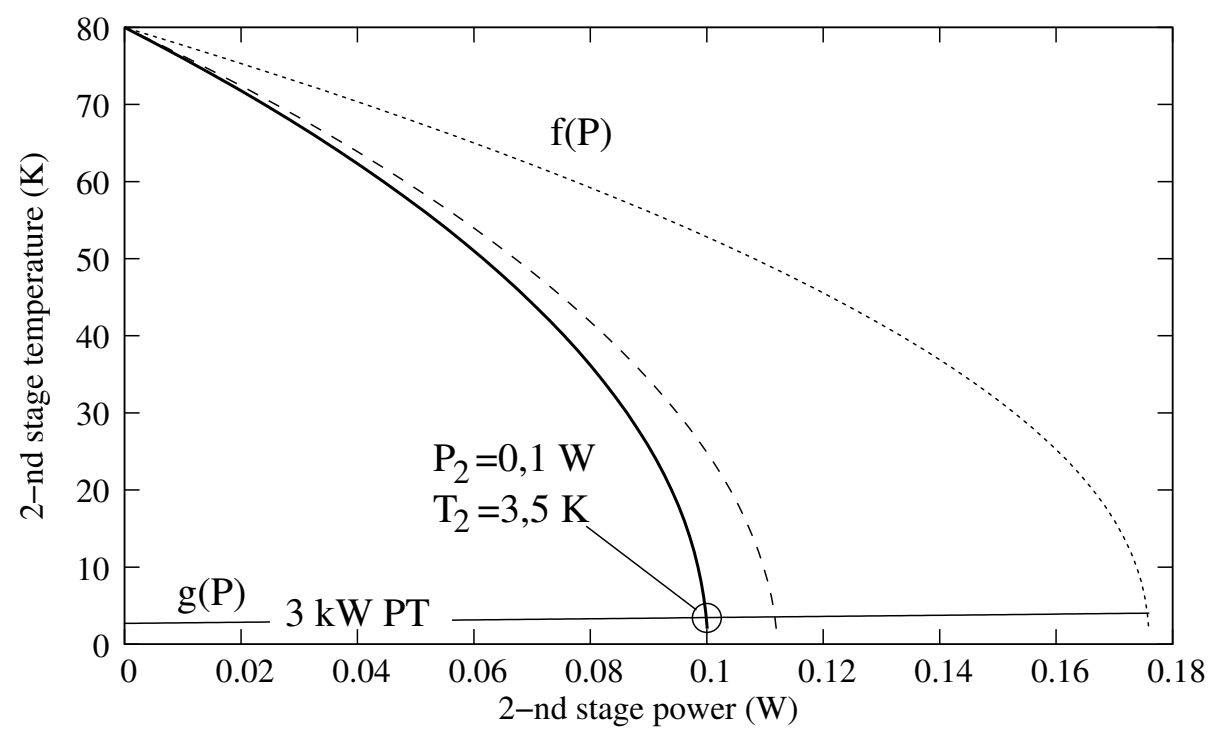

Figure 7: Simulation of the PT $2^{\text {st }}$-stage. $f(P)$ for several suspensions: stainless steel tubes (dotted line), G-10 fiber rods (dashed line), Mylar rods (bold line). $g(P)$ for a $3 \mathrm{~kW}$ cryocooler (solid line).

lar suspensions can be simply realized using a 3-D printer. Fig. 8 8 a shows the copper braids and the 3-D printed V-shaped Mylar suspension.
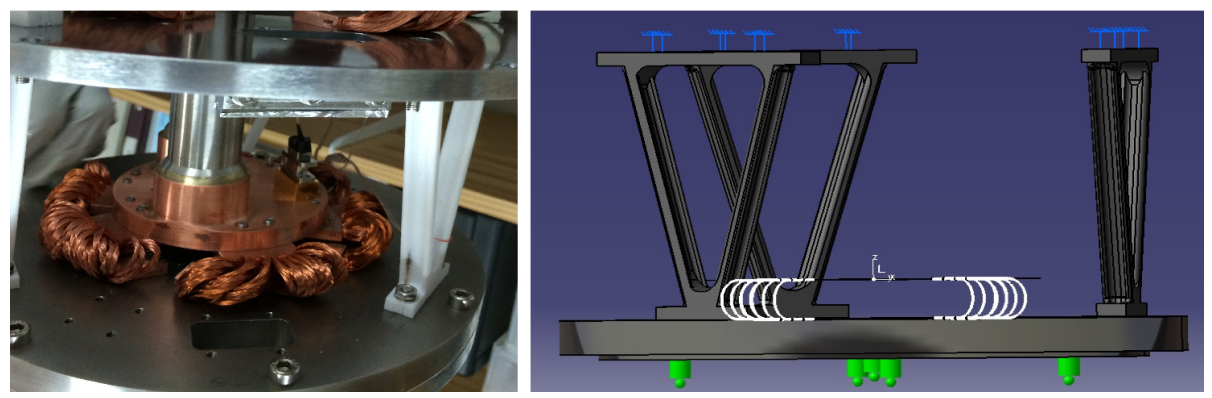

Figure 8: a) Picture showing the $2^{\text {nd }}$ stage Mylar suspensions and the copper braids. b) CAD model used for mechanical analysis. 


\section{Finite Elements Simulations}

The previous calculations demonstrate that the principle of a low power

190

report on the whole complexity of the cryostat. For example, thermal gradients or more complex mechanical resonance modes are not taken into account. These perturbations could have detrimental impact on the CSO frequency stability. Finite Element Models have thus been implemented to confirm the previous 195 results.

\subsection{Mechanical FE simulations}

Fig. $8 \mathrm{~b}$ shows the mechanical FE model used to simulate the behavior of the $2^{\text {nd }}$ stage suspension. The thermal shield as well as the resonator assembly are considered as infinitely rigid and thus are replaced by masses attached to the stainless steel ballast. We neglect the shape of the copper braids and thus assume that they behave like straight beam submitted to a flexion force. A copper braid containing 2700 wires is modelised as a unique equivalent copper beam. Its diameter has been chosen to get the same stiffness of 2700 independant wires acting in parallel. As the stiffness of a flexion beam is proportional to the $2054^{\text {th }}$ power of its diameter, the equivalent beam diameter is $\Phi \times \sqrt[4]{2700} \approx 0.4 \mathrm{~mm}$. Fig. 9 shows the first mechanical modes for the two types of Mylar suspension: vertical rods and V-shaped suspensions.

In a second step, a periodic displacements $z_{1}(t)$ at $1 \mathrm{~Hz}$ is imposed to the 210 ballast is calculated. The amplitude ratio $Z / Z_{1}$ gives the mechanical damping in the axial direction. The same procedure has been applied for the transverse direction. The results is given in the table 4.

As expected in the simplest configuration using three vertical rods, the axial 215 stiffness $k_{0}$ is high leading to a resonance frequency $f_{0}=190 \mathrm{~Hz}$ and a large mechanical damping. Conversely the pendulum mode appears at $13 \mathrm{~Hz}$ and the 

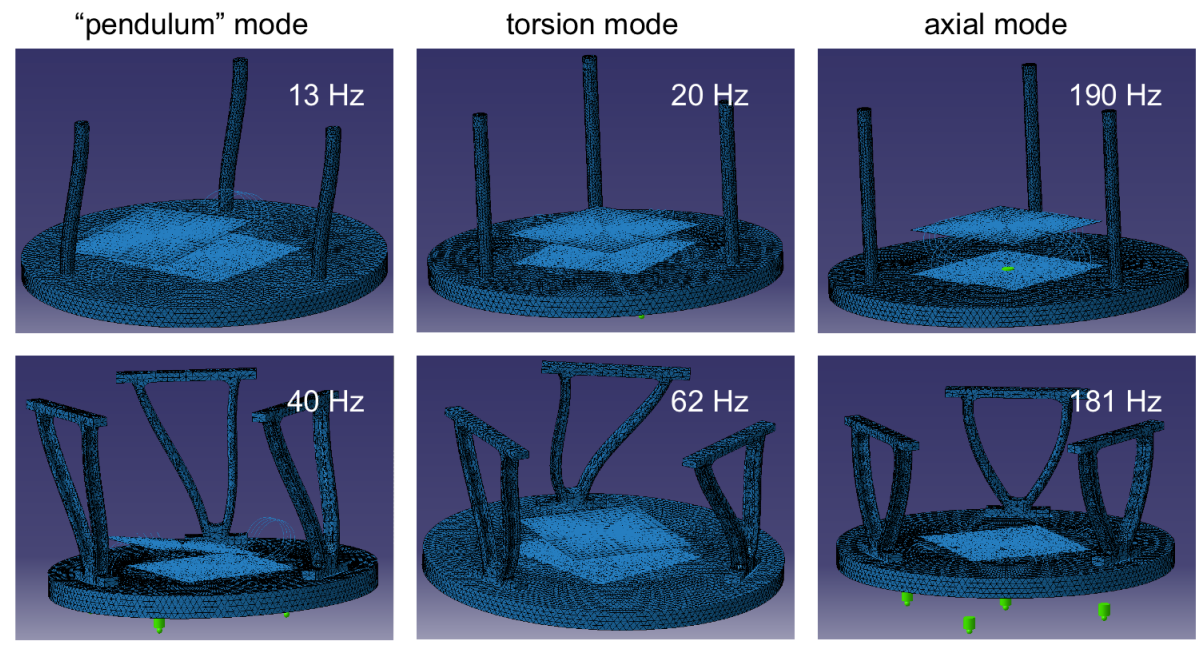

Figure 9: First mechanical modes of the $2^{\text {nd }}$-stage for the two types of suspensions made in Mylar. Upper figures: Mylar rods. Lower figures: Mylar V-shapped suspensions.

Table 4: Mechanical damping in the axial and transverse directions.

\begin{tabular}{lcc}
\hline Suspension type & $\begin{array}{c}\text { Axial } \\
\text { damping }\end{array}$ & $\begin{array}{c}\text { Transverse } \\
\text { damping }\end{array}$ \\
\hline Cylindrical rods & $85 \mathrm{~dB}$ & $43 \mathrm{~dB}$ \\
V-Shaped & $85 \mathrm{~dB}$ & $62 \mathrm{~dB}$ \\
\hline
\end{tabular}

mechanical damping is only $43 \mathrm{~dB}$. The V-shaped suspension allows an increase in stiffness in the transverse direction without affecting too much the behavior in the axial direction. The torsion mode can not be evaluated in the previous approach. Its resonance frequency is $20 \mathrm{~Hz}$ and $62 \mathrm{~Hz}$ for the vertical rod and the $\mathrm{V}$-shaped suspensions respectively.

\subsection{Thermal FE simulations}

We simulated only the $2^{\text {nd }}$ stage assuming the $1^{\text {st }}$ stage stabilized at $80 \mathrm{~K}$. Fig. 10 shows the thermal ballast and the cavity. The hottest points $(\sim 5.2 \mathrm{~K})$ 225 correspond to the suspension fastening, the coldest $(\sim 2.8 \mathrm{~K})$ to those of the copper braids. The temperature is homogeneous in the whole cavity volume, with a maximal gradient of $1 \mathrm{mK}$. 


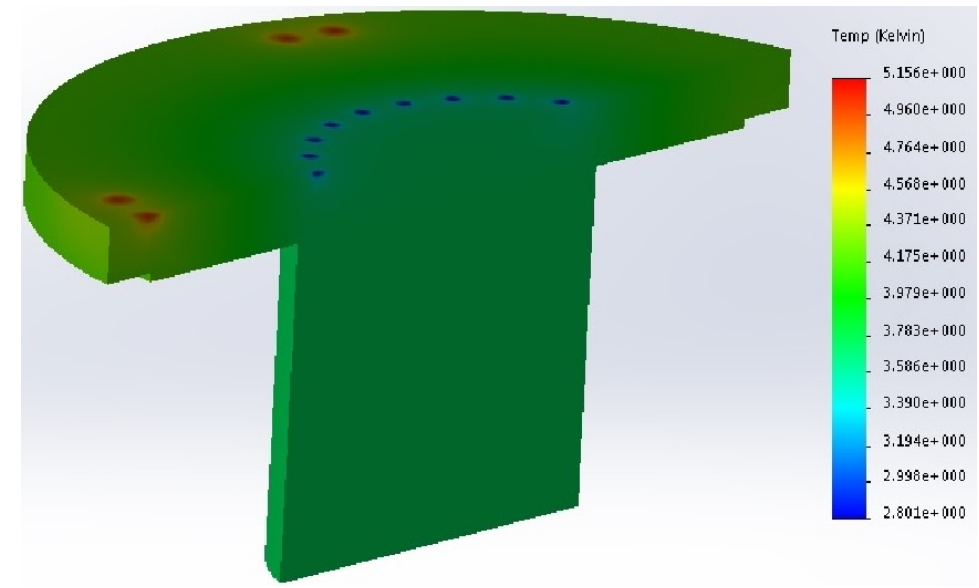

Figure 10: Finite elements simulation of the $2^{\text {nd }}$ stage. Only the thermal ballast and the cavity are represented.

A this step of development and in spite of their relative simplicity, the previous models are considered reliable enough to undertake the construction of a prototype. The models can be possibly refined in a second stage if needed.

\section{Resonator validation}

A resonator was assembled and mounted inside the cryostat. The sapphire resonator is made from a Kyropoulos monocrystal [9. It presents a high Qfactor mode at $\nu_{0} \sim 10 \mathrm{GHz}$. The temperature evolution during the cool down

235 is shown in Fig. 11 .

The minimum achievable resonator temperature is $4.1 \mathrm{~K}$, fully compliant with the specification. Fig. 12 shows the modulus of the resonator response around the whispering gallery mode at $\nu_{0} \sim 10 \mathrm{GHz}$ measured at $4.1 \mathrm{~K}$. The bandwidth is $7.2 \mathrm{~Hz}$ equivalent to a loaded Q-factor $Q_{L} \sim 1.4 \times 10^{9}$.

The resonator temperature is stabilized using a commercial temperature controller. The sensor is a Cernox type CX-1050 with a sensitivity of approximately $-430 \Omega / \mathrm{K}$. By changing the temperature set-point step-by-step we obtain the resonator frequency evolution (see Fig. 13). The resonator presents a turnover temperature equals to $5.24 \mathrm{~K}$. Stabilized at this point, its frequency is no longer 


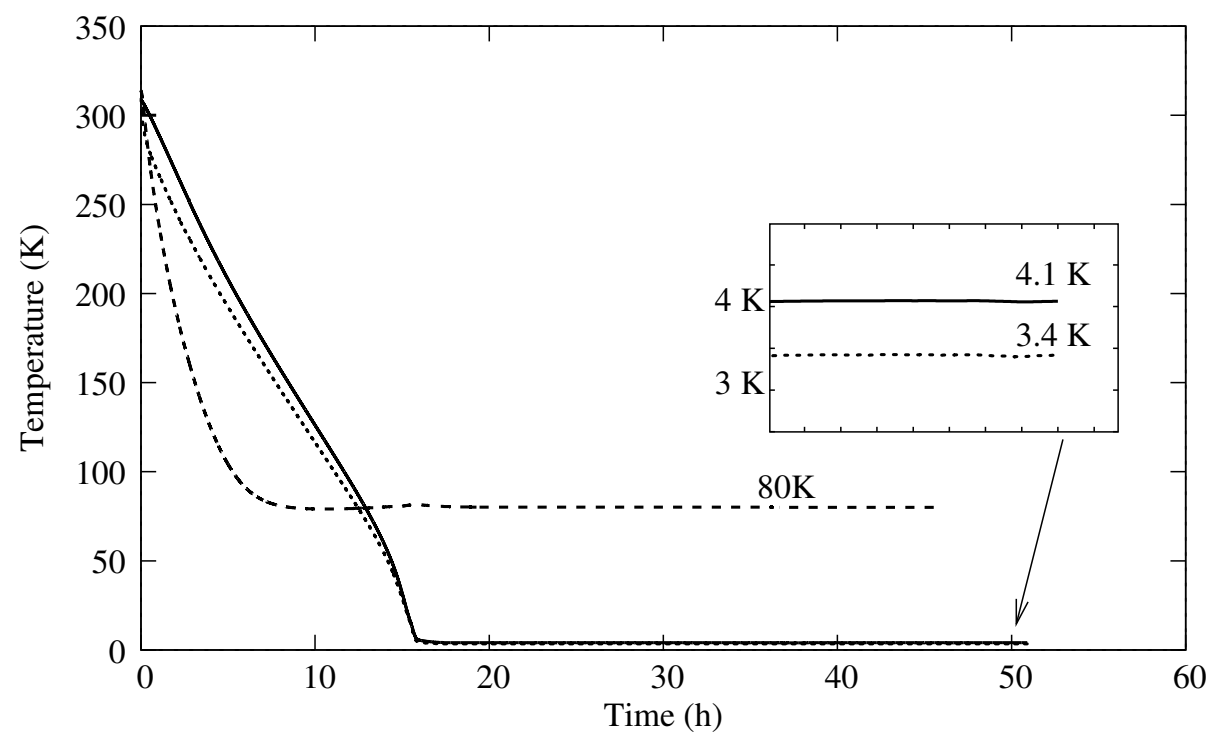

Figure 11: Temperatures evolution during cool-down. Resonator temperature (bold line), $2^{\text {nd }}$-stage shield temperature (dotted line), $1^{\text {st }}$ stage shield temperature (dashed line).

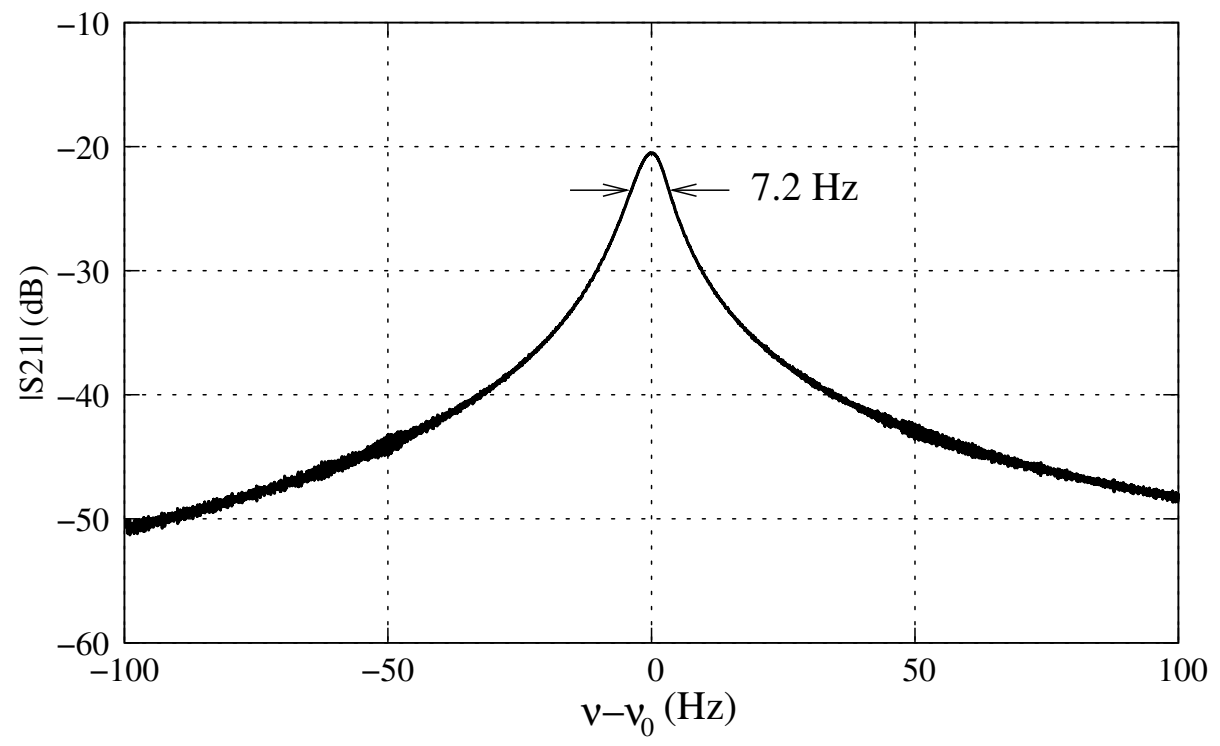

Figure 12: Transmissiom resonator response around the resonance frequency $\nu_{0} \approx 10 \mathrm{GHz}$.

sensitive to the temperature fluctuations and a high frequency stability can be obtained. 


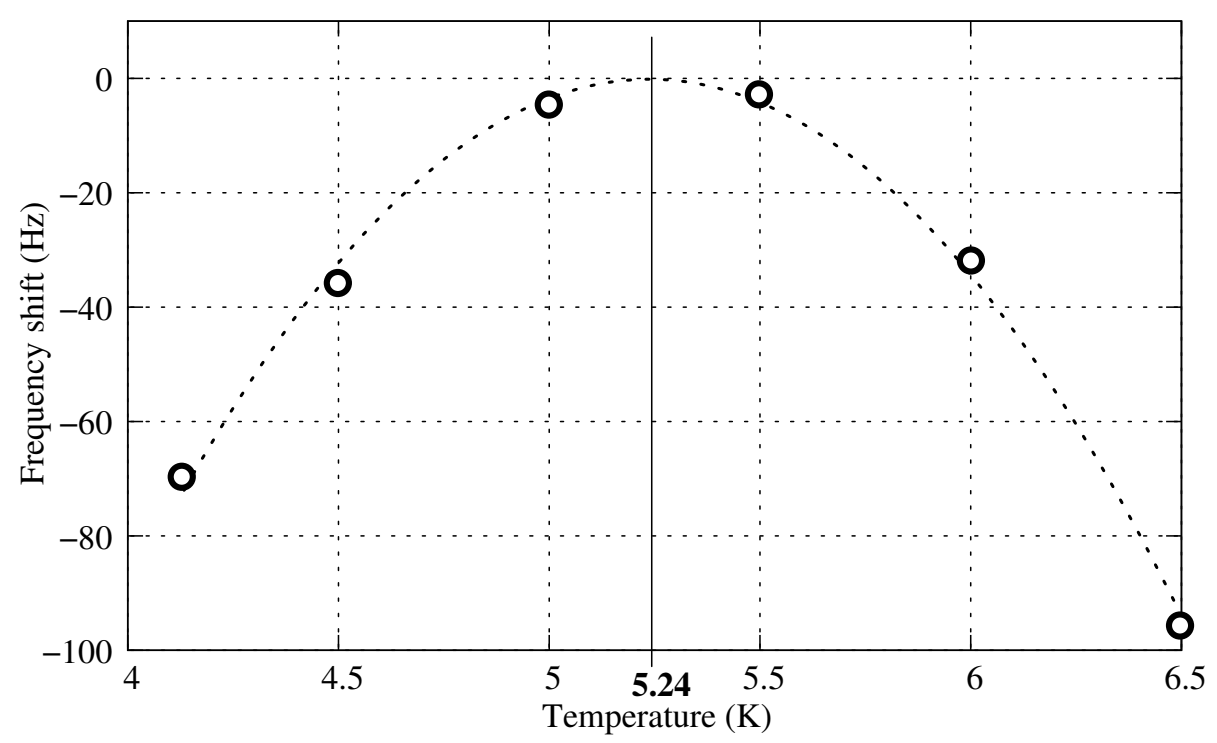

Figure 13: Resonator frequency evolution around the turnover temperature.

\section{Oscillator preliminary evaluation}

This resonator has been inserted in an oscillator loop complemented with a Pound servo and a power stabilization. The oscillator delivers $10 \mathrm{dBm}$ at $\nu_{0}=10.02 \mathrm{GHz}$.

We implemented in our laboratory a set of three ultra-stable $6 \mathrm{~kW}$ CSOs. This set constitutes one of the reference of the Oscillator IMP metrological platform dedicated to the measurement of noise and short-term frequency stability of oscillators. The exceptional performance of these CSOs have been reported in 21]. These three CSOs have recently been moved in a temperature stabilized room at $22^{\circ} \mathrm{C} \pm 0.5^{\circ} \mathrm{C}$. The new prototype stays in another experimental room equipped only with the standard air-conditioning system of the flat. Depending on the sunlight the temperature near the cryostat can vary of several degrees during the day.

In a first step, the close-to-carrier phase noise of the prototype has been 
evaluated. Its $10 \mathrm{GHz}$ output signal is mixed with those delivered by one of the ultra-stable $6 \mathrm{~kW}$ CSO. The obtained $26 \mathrm{MHz}$ beatnote is sent to a Symmetricom 5125A phase noise test set. The observed phase noise is shown in the Fig. 14. The upper curve was recorded when the springs supporting the PT cold-head were ntentionally blocked: the bolt getting through every spring was tightened. In this case the vibration of the cold-head are almost integrally transferred to the cryostat. The spectrum shows a large line at $1.47 \mathrm{~Hz}$ and its harmonics, which are the signature of the cold-head vibration. The other smaller line at $1.41 \mathrm{~Hz}$ comes from the $6 \mathrm{~kW}$ CSO. When the springs are released (see Fig. 14 lower curve), the $1.47 \mathrm{~Hz}$ line almost completely disappears and its harmonics are also strongly attenuated. From this second spectrum, the resonator displacement is estimated to be less than $0.1 \mu \mathrm{m}$.
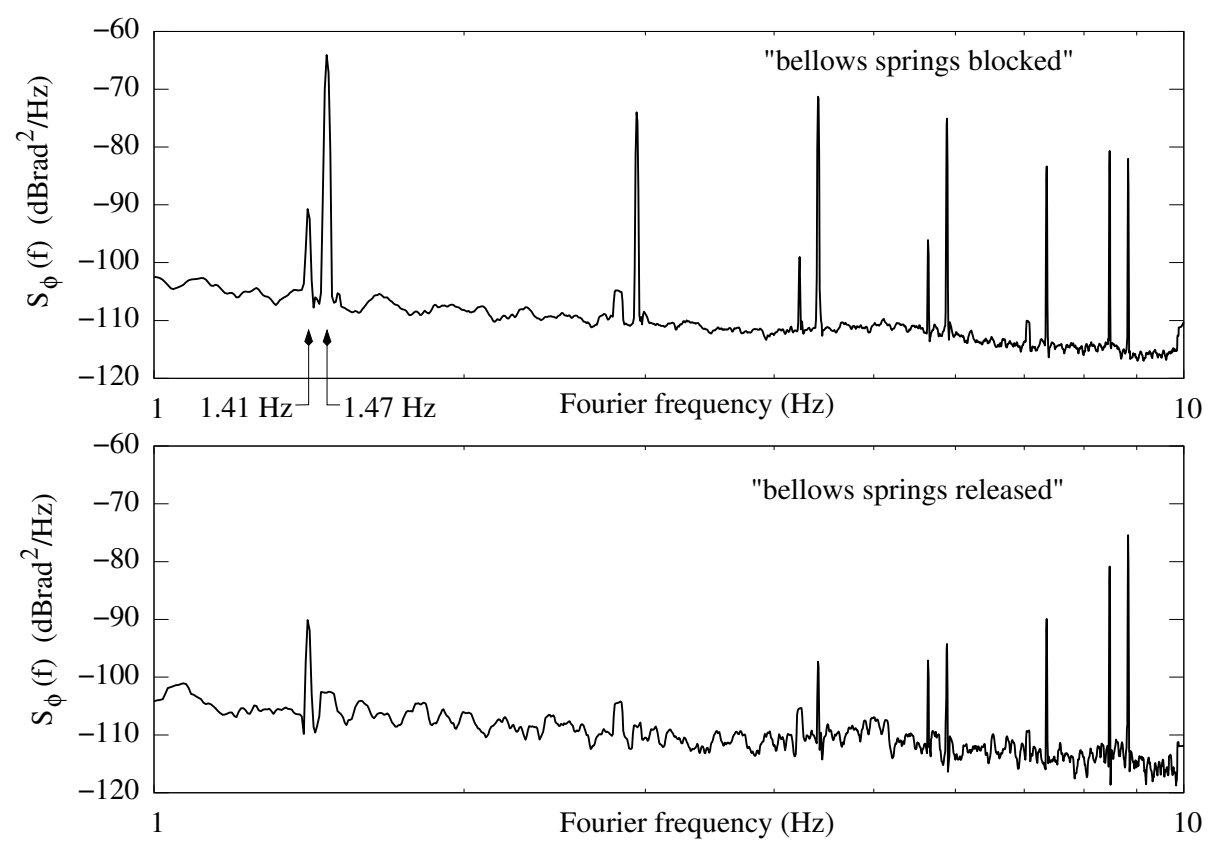

Figure 14: Upper curve: Phase noise when the bellows springs are blocked. Lower curve: bellows springs realesed.

To evaluate the frequency performance of the prototype, it has been simultaneously compared to two high stability $6 \mathrm{~kW}$ CSOs. The three-cornered-hat 
method [21, 22] has been used to extract the prototype fractional frequency stability. The result is presented in the Fig. 15. The new instrument presents

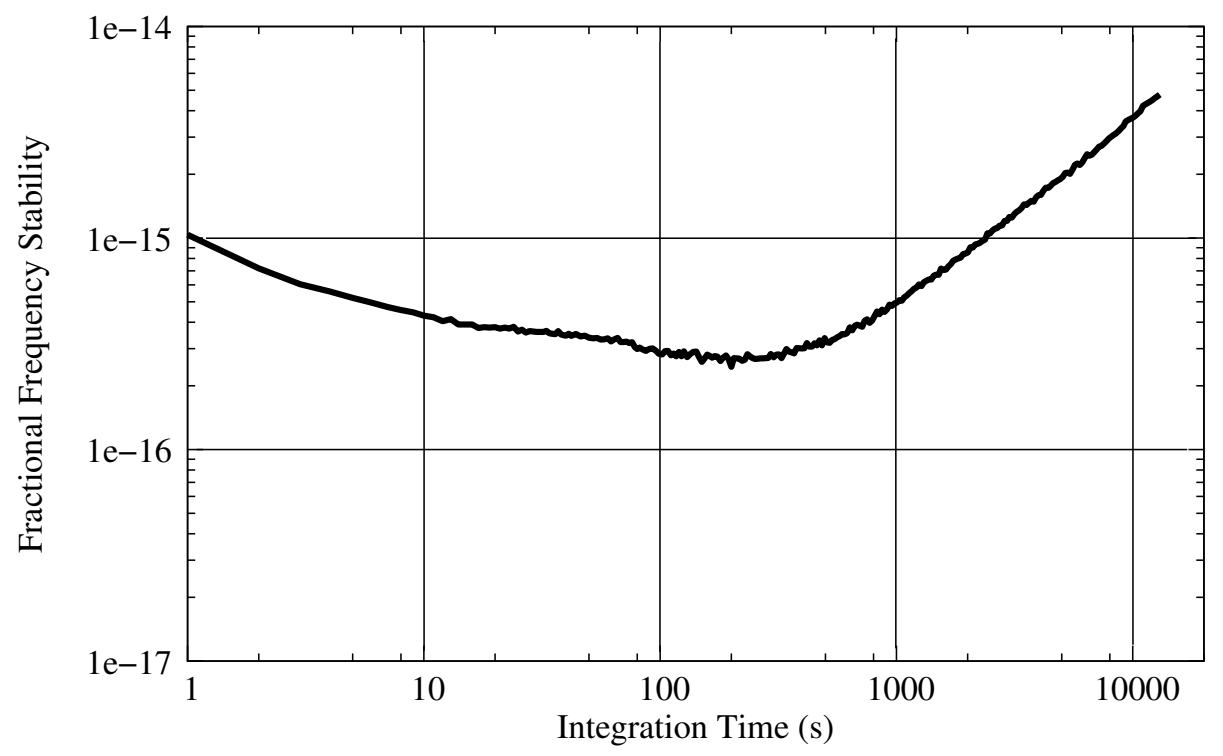

Figure 15: Fractional frequency stability of the $3 \mathrm{~kW}$ prototype evaluated using the threecornered-hat-method with two ultra-stable $6 \mathrm{~kW}$ CSO used as references 21.

a fractional short term frequency stability below $1 \times 10^{-15}$. At long integration time the fractional frequency stability is degraded proportionnaly to $\tau$. The observed drift (approximately $3 \times 10^{-14} /$ day) could result from the large temperature variations inside the laboratory.

\section{Conclusion}

A new cryostat has been designed to cool-down a sapphire microwave resonator intented to serve as the frequency reference of an ultra-stable oscillator. This new cryostat is equipped with a $3 \mathrm{~kW}$ PT cryocooler sufficient to reach a temperature of $4.1 \mathrm{~K}$. A specially designed suspension permits to filter the $1.4 \mathrm{~Hz}$ vibration generated by the pulse-tube. A preliminary performance evaluation shows a short term fractional frequency stability below $1 \times 10^{-15}$ for $1 \mathrm{~s} \leq \tau \leq 2000 \mathrm{~s}$. 


\section{References}

[1] M. A. Green, The effect of low temperature cryocoolers on the development of low temperature superconducting magnets, IEEE Transactions on Applied Superconductivity 11 (2001) 2615-2618.

[2] R. Radebaugh, Cryocoolers: the state of the art and recent developments contribution of NIST, Journal of Physics: Condensed Matter 21 (2009) 164219 .

[3] V. Giordano, S. Grop, C. Fluhr, B. Dubois, Y. Kersalé, E. Rubiola, The autonomous cryocooled sapphire oscillator: A reference for frequency stability and phase noise measurements, Journal of Physics: Conference Series 723 (2016) 012030.

[4] G. J. Dick, N. T. Wang, Stability and phase noise tests of two cryocooled sapphire oscillators, IEEE Transactions on Ultrasonics, Ferroelectrics and Frequency Control 47 (2000) 1098-1101.

[5] J. Hartnett, N. Nand, Ultra-low vibration pulse-tube cryocooler stabilized cryogenic sapphire oscillator with $10^{-16}$ fractional frequency stability, IEEE Transactions on Microwave Theory and Techniques 58 (2010) 35803586.

[6] V. Giordano, S. Grop, B. Dubois, P.-Y. Bourgeois, Y. Kersalé, E. Rubiola, G. Haye, V. Dolgovskiy, N. Bucalovicy, G. D. Domenico, S. Schilt, J. Chauvin, D. Valat, New generation of cryogenic sapphire microwave oscillator for space, metrology and scientific applications, Review of Scientific Instruments 83 (2012) 085113.

[7] S. Grop, P. Y. Bourgeois, N. Bazin, Y. Kersalé, E. Rubiola, C. Langham, M. Oxborrow, D. Clapton, S. Walker, J. De Vicente, V. Giordano, ELISA: A cryocooled $10 \mathrm{GHz}$ oscillator with $10^{-15}$ frequency stability, Review of Scientific Instruments 81 (2010) 025102. 
[8] A. G. Mann, A. J. Giles, D. G. Blair, M. J. Buckingham, Ultrastable cryogenic sapphire dielectric microwave resonators: mode frequencytemperature compensation by residual paramagnetic impurities, J. Phys. D: Appl. Phys. 25 (1992) 1105-1109.

[9] V. Giordano, C. Fluhr, S. Grop, B. Dubois, Tests of sapphire crystals manufactured with different growth processes for ultra-stable microwave oscillators, IEEE Transactions on Microwave Theory and Techniques 64 (2016) 78-85.

[10] C. R. Locke, E. N. Ivanov, J. G. Hartnett, P. L. Stanwix, M. E. Tobar, Invited article: Design techniques and noise properties of ultrastable cryogenically cooled sapphire-dielectric resonator oscillators, Review of Scientific Instruments 79 (2008) 051301.

[11] S. Grop, W. Schäfer, P.-Y. Bourgeois, Y. Kersalé, M. Oxborrow, E. Rubiola, V. Giordano, Unprecedented high long term frequency stability with a microwave resonator oscillator, IEEE Transactions on Ultrasonics, Ferroelectrics and Frequency Control 58 (2011) 1694-1697.

[12] J. G. Hartnett, N. R. Nand, C. Wang, J.-M. L. Floch, Cryogenic sapphire oscillator using a low-vibration design pulse-tube cryocooler: first results, IEEE Transactions on Ultrasonics, Ferroelectrics, and Frequency Control 57 (2010) 1034-1038.

[13] M. Oxborrow, K. Benmessai, S. Grop, N. Bazin, P. Bourgeois, Y. Kersalé, V. Giordano, g-sensitivity of a cryogenic sapphire resonator, in: Proc. 22nd European Frequency and Time Forum, Toulouse, France, 2008, pp. FPE-062.

[14] C. Wang, P. E. Gifford, Development of $4 \mathrm{~K}$ pulse tube cryorefrigerators at Cryomech, Advances in Cryogenic Engineering: Proceedings of the Cryogenic Engineering Conference-CEC 613 (2002) 641-648. 
[15] S. Caparrelli, E. Majorana, V. Moscatelli, E. Pascucci, M. Perciballi, P. Puppo, P. Rapagnani, F. Ricci, Vibration-free cryostat for low-noise applications of a pulse tube cryocooler, Review of Scientific Instruments 77 (2006) 1-7.

[16] C. Wang, J. G. Hartnett, A vibration free cryostat using pulse tube cryocooler, Cryogenics 50 (2010) 336-341.

[17] T. Tomaru, T. Suzuki, T. Haruyama, T. Shintomi, N. Sato, A. Yamamoto, Y. Ikushima, R. Li, T. Akutsu, T. Uchiyama, S. Miyoki, Cryocoolers 13, Vibration-Free Pulse Tube Cryocooler System for Gravitational Wave Detectors, Part I: Vibration-Reduction Method and Measurement, 2005, pp. 695-702.

[18] L. Meirovitch, Fundamentals of vibrations, McGraw-Hill Companies, 2001.

[19] http://www.cryomech.com/.

[20] G. K. White, Experimental techniques in low-temperature physics, Clarendon Press, 1979.

[21] C. Fluhr, S. Grop, B. Dubois, Y. Kersalé, E. Rubiola, V. Giordano, Characterization of the individual short-term frequency stability of cryogenic sapphire oscillators at the $10^{-16}$ level, IEEE Transactions on Ultrasonics, Ferroelectrics and Frequency Control 63 (2016) 915-921.

[22] J. Gray, D. Allan, A method for estimating the freqeuncy stability of an individual oscillator, in: Proc 28th Ann. Symp. on Frequency Control., Fort Monmouth, (NJ) US, 1974, pp. 243-246. 